\title{
Characterization and diversity of magnetotactic bacteria from sediments of Caroline Seamount in the western Pacific Ocean
}

CUI Kaixuan ${ }^{1,2,3,4}$, ZHANG Wenyan ${ }^{1,2,4,5}$, LIU Jia ${ }^{1}$, XU Cong ${ }^{1,7}$, ZHAO Yicong $^{1,2,3,4}$, CHEN $\mathrm{Si}^{1,2,3,4}$, PAN Hongmiao ${ }^{1,2,4,5, * *}$, XIAO Tian ${ }^{1,2,4,5,{ }^{* *}}$, WU Long-Fei ${ }^{5,6}$

CUI et al.: Diversity of magnetotactic bacteria in Caroline Seamount

${ }^{1}$ CAS Key Laboratory of Marine Ecology and Environmental Sciences, Institute of Oceanology, Chinese Academy of Sciences, Qingdao 266071, China

${ }^{2}$ Laboratory for Marine Ecology and Environmental Science, Qingdao National Laboratory for Marine Science and Technology, Qingdao 266000, China

${ }^{3}$ University of Chinese Academy of Sciences, Beijing 100049, China

${ }^{4}$ Center for Ocean Mega-Science, Chinese Academy of Sciences, Qingdao 266071, China

5 International Associated Laboratory of Evolution and Development of Magnetotactic Multicellular Organisms (LIA-MagMC), CNRS-CAS, Marseille-Beijing-Qingdao-Sanya

${ }^{6}$ Aix Marseille Univ, CNRS, LCB, IM2B, IMM, Marseille, 13009, France

${ }^{7}$ National Oceanographic Center, Qingdao 266071, China

* Supported by the National Natural Science Foundation of China (Nos. 41776130 \& 41776131), the National Natural Science Foundation of China-Shandong Joint Fund (U1706208), the Youth Talent Support Program of the Laboratory for Marine Ecology and Environmental Science, Pilot National Laboratory for Marine Science and Technology (Qingdao) (LMEES-YTSP-2018-01-07), and the Science \& Technology Basic Resources Investigation Program of China (2017FY100803). ** Corresponding author: panhongmiao@qdio.ac.cn; txiao@qdio.ac.cn

\footnotetext{
Abstract Magnetotactic bacteria (MTB) are a group of microorganisms capable of orientating and swimming along magnetic fields because they contain intracellular biomineralized magnetosomes composed of magnetite $\left(\mathrm{Fe}_{3} \mathrm{O}_{4}\right)$ or/and greigite $\left(\mathrm{Fe}_{3} \mathrm{~S}_{4}\right)$. They are ubiquitous in freshwater, brackish, and marine habitats, and are cosmopolitan in distribution. However, knowledge of their occurrence and distribution in seamount ecosystems is limited. In this study we investigated the diversity and distribution of MTB in the Caroline Seamount (CM4). The
} 
abundance of living MTB at 12 stations varying in depth from 90 to $1545 \mathrm{~m}$ was $1.1-43.7 \times 10^{3} \mathrm{ind} . / \mathrm{dm}^{3}$. Despite diverse shapes of MTB observed, magnetotactic cocci were the dominant morphotype and could be categorized into two types: (i) typical cocci that appeared to have peritrichous flagella; and (ii) those characterized by having a drop-shaped form and one bundle of flagella located at the thin/narrow end of the cell. Transmission electron microscopy (TEM) analysis revealed that the magnetosomes formed by those magnetotactic cocci are magnetite $\left(\mathrm{Fe}_{3} \mathrm{O}_{4}\right)$ with octahedral crystal habit. A total of 41 operational taxonomic units (OTUs) of putative MTB (2 702 reads) were acquired from nine stations, based on high-throughput sequencing. Of these, 40 OTUs belonged to the Proteobacteria phylum and one belonged to the Nitrospirae phylum. We found apparent connectivity between the MTB populations on the Caroline and Kexue seamounts, although the diversity of MTB on Caroline was much richer than on the Kexue Seamount. Our results imply that the unique topography of seamounts and other as-yet unclear environmental factors could lead to evolution of different flagella arrangements in magnetotactic cocci, and the occurrence of octahedral magnetite magnetosomes.

Keyword: magnetotactic bacteria; Caroline Seamount; abundance; diversity; magnetosome

\section{INTRODUCTION}

Magnetotactic bacteria (MTB) are a group of Gram-negative bacteria that biomineralize unique membrane-enveloped, single magnetic domain, iron oxide $\left(\mathrm{Fe}_{3} \mathrm{O}_{4}\right.$, magnetite) or/and iron sulfide $\left(\mathrm{Fe}_{3} \mathrm{~S}_{4}\right.$, greigite) nanoparticles termed magnetosomes. Within MTB, magnetosomes act as a compass needle, and the flagellar apparatus enables it to swim along magnetic field lines in a behavior termed magnetotaxis (Bazylinski and Frankel 2004). MTB are a morphologically, phylogenetically, and metabolically diverse group of prokaryotes (Lefèvre and Wu 2013). Diverse morphologies of MTB have been described, including coccus, ovoid, vibrio, rod, spirillum, and multicellular aggregates (Farina et al. 1983; Abreu et al. 2007; Isambert et al. 2007; Lefèvre et al. 2007; Lin et al. 2009; Lefèvre et al. 2011a). Based on NCBI taxonomy, the MTB are phylogenetically affiliated with diverse phyla of the domain Bacteria, including the Proteobacteria, Nitrospirae, and Planctomycetes phyla, and the candidate Omnitrophica (previously named as candidate division OP3) and Latescibacteria (previously named as candidate division WS3) phyla (Lefèvre and Bazylinski 2013; Lin and Pan 2015; Kolinko et al. 2016; Lin et al. 2017). Recent studies of reconstructed metagenome-assembled MTB genomes have expanded knowledge of the taxonomy of MTB. For example, 168 genomes were retrieved and classified as 
belonging to 13 bacterial phyla, based on GTDB (Genome Taxonomy Database) taxonomy, and 7 phyla have been classified based on NCBI taxonomy (Lin et al. 2020). In another study, 38 novel MTB draft genomes were reconstructed, several of which were related to the phyla Elusimicrobia, Candidatus Hydrogenedentes, and Nitrospinae (Uzun et al. 2020).

MTB are model organisms for investigating biomineralization processes because of their capacity for intracellular production of magnetite or greigite crystals in a process controlled by the magnetosome gene cluster (MGC) (Lin et al. 2017). MTB biomineralize diverse shapes of magnetosomes, including octahedral, cubo- octahedral, elongated- prismatic or parallelepipedal, bullet- shaped and pleomorphic forms (Bazylinski et al. 2013a; Amor et al. 2020; Li et al. 2020a). Intriguingly, it has been reported that the morphological diversity of magnetosomes is strongly correlated with specific phylogenetic taxa of MTB (Pósfai et al. 2013; Li et al. 2020a; Liu et al. 2021). For example, cuboctahedral or elongated-prismatic magnetite magnetosomes are synthesized in the groups of the Alpha-, Eta-, and Gamma-proteobacteria of MTB, while bullet-shaped magnetite magnetosomes are produced by the Deltaproteobacteria class, and the phyla of Nitrospirae and Omnitrophica (Pósfai et al. 2006; Li et al. 2010a; Lefèvre et al. 2011c; Lin et al. 2011; Kolinko et al. 2012; Lefèvre et al. 2012; Zhou et al. 2012; Lefèvre and Bazylinski 2013; Zhang et al. 2013; Li et al. 2015; Li et al. 2017; Zhang et al. 2017; Li et al. 2019; Amor et al. 2020; Li et al. 2020a; Li et al. 2020b). However, diverse morphologies of greigite crystals, including bullet- shaped, cubo- octahedral, elongated- prismatic, and pleomorphic, only can be synthesized in Deltaproteobacteria MTB (Lefèvre and Bazylinski 2013).

Magnetotactic cocci were the dominant morphotype of MTB in natural freshwater and marine habitats (Spring et al. 1998; Flies et al. 2005a; Lin et al. 2009; Du et al. 2017) including sediments in lakes (Lin et al. 2009), rivers (Kozyaeva et al. 2017), estuaries (Zhang et al. 2017), intertidal zones (Pan et al. 2008; Chen et al. 2015), lagoons (Du et al. 2017), continental shelves (Xu et al. 2018), and seamounts (Liu et al. 2017). Magnetotactic cocci belonged to the order Magnetococcales have recently been transferred from the Alphaproteobacteria to "Candidatus Etaproteobacteria", based on ribosomal proteins, MTB core genes, whole genome analysis of the MO-1 and MC-1 strains, and a large-scaled identification and phylogenetic analysis on twenty novel magnetotactic cocci (Ji et al. 2017; Zhang et al. 2017; Lin et al. 2018; Liu et al. 2021). Many novel magnetotactic cocci species have been described as having differences in magnetosome 
chain configurations, and the number, crystal size, and morphology of magnetosomes (Meldrum et al. 1993; Lefèvre et al. 2009; Zhang et al. 2017; Liu et al. 2021). For instance, various models of MTB chain configuration have been reported among the cocci, including single chain, double separated chains, double parallel chains, double bundles containing two parallel chains in each bundle, particle aggregates, and other irregular forms (Liu et al. 2021). Elongated prismatic and (elongated) cuboctahedral magnetite crystals have commonly been reported to occur in the order Magnetococcales and had a relatively consistent morphology (Pósfai et al. 2013). However, a unique form of (elongated) octahedral magnetosomes have been described in the uncultured freshwater magnetotactic coccus strains SHHC-1 and MYC-5, the former having the crystals arranged in two double chains and the latter in two chains (Zhang et al. 2017; Liu et al. 2020). Similar crystals arranged in a chain have also been observed in the cultured MTB strain Magnetofaba australis IT-1, which was isolated from sediments of a brackish-marine coastal lagoon (Araujo et al. 2016).

Magnetotactic bacteria are ubiquitous in natural environments, and peak in abundance at the oxic-anoxic transition zone (OATZ) in sediments or chemically stratified water columns in freshwater, brackish, marine, and hypersaline habitats (Bazylinski and Frankel 2004; Moskowitz et al. 2008; Bazylinski et al. 2013a). Recent investigations of MTB diversity at the Kexue Seamount have extended our knowledge of the adaptability of MTB to this tropical oligotrophic marine habitat (Liu et al. 2017). Seamounts have numerous unique topographic characteristics including acceleration and recirculation of currents (Dower et al. 1992), Taylor columns (Hogg 1973; Genin and Boehlert 1985), and internal waves (Kunze and Sanford 1996) that potentially support diversity hotpots in oligotrophic oceans (Mendonça et al. 2012). The Kexue Seamount (also designated M2) is situated at the junction of the Yap and Mariana trenches, where complex dynamic hydrological variations can occur dramatically. Intriguingly, 16 novel MTB species specific to this seamount were identified, and phylogenetic analysis showed endemic adaptation of the MTB to the seamount. Some of the magnetotactic cocci from this seamount have the most sophisticated flagellar apparatus known, involving 19 flagella organized in a 3:4:5:4:3 array enveloped in a flagellar bundle (Liu et al. 2017). However, studies of the distribution, diversity, and characterization of MTB from seamount ecosystems remain limited. In this study, sediments were collected from the Caroline Seamount (CM4) in the western Pacific Ocean. Various shapes 
of MTB were identified using transmission electron microscope (TEM) investigations. The dominate MTB population was magnetotactic cocci that formed magnetite-type magnetosomes with octahedral morphology. Analysis using high-throughput 16S rRNA sequencing indicated the occurrence at this seamount of 41 putative MTB operational taxonomic units (OTUs) affiliated to the phyla Proteobacteria and Nitrospirae. We further compared the diversity and characteristics of MTB between the Caroline and Kexue seamounts, and discussed possible explanations for the specificity of MTB and their magnetosomal biomineralization in these seamount habitats.

\section{MATERIAL AND METHOD}

\subsection{Sediment sampling}

Sediment samples were collected in the tropical western Pacific Ocean from the Caroline Seamount $\left(\mathrm{CM} 4,10.3-10.9^{\circ} \mathrm{N}, 139.9-140.4^{\circ} \mathrm{E}\right)$ during cruise WPOS-M4 conducted by the Chinese research vessel Kexue from 7 August to 5 September, 2017. The peak of the seamount is $57 \mathrm{~m}$ below the sea surface and it has a height of $5950 \mathrm{~m}$. Samples were collected from 13 stations at various depths (90-2 $805 \mathrm{~m})$ in the seamount area (Figs.1 and 2a) using the remotely operated vehicle (ROV) Faxian (Fugro Geosolutions, Shenzhen, China). On return to the main vessel the sediments and seawater (ratio 1:1) were immediately transferred into 500-ml plastic bottles and incubated in dim light at ambient temperature $\left(\sim 20^{\circ} \mathrm{C}\right)$ for subsequence research. In parallel, approximately $50 \mathrm{~g}$ sediment samples from each station were transferred to sterile sealed bags and stored at $-80^{\circ} \mathrm{C}$ for later DNA extraction.
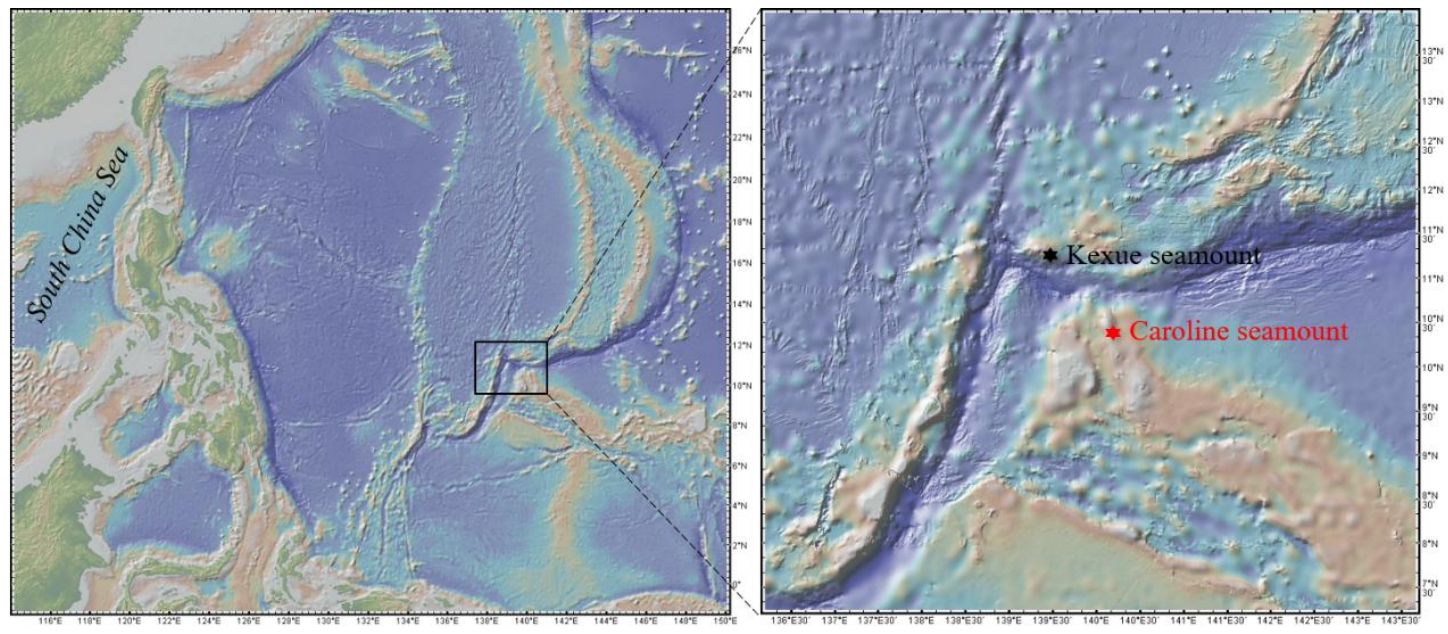

Fig.1 Location of the sampling area and the Caroline Seamount

Sampling area in the tropical western Pacific Ocean (black rectangle in the left figure) and the location of the Caroline Seamount (red hexagram in the right figure). The maps were generated using the GeoMapApp version 


\subsection{Optical and electron microscopy}

MTB in the sediments were enriched magnetically for observation on aboard immediately after sampling. Each plastic bottle was shaken to mix the sediment and seawater, then two magnets with opposite sides were attached to the outside of the bottle adjacent to the interface of the seawater and sediment. After 40 min the MTB that concentrated at the interface adjacent to the magnets were removed using a Pasteur pipette and transferred into a clean $1.5 \mathrm{ml}$ tube. The MTB were inspected and counted using the hanging drop technique (Schüler 2002) and an Olympus CX31 microscope. The abundance of MTB was calculated according to the formula A = N/V (A: abundance; N: number of MTB; V: volume of sediment), as previously described (Xu et al. 2018).

Subsequently, the enriched MTB were purified using the modified race-track method with a 1 ml pipette tip to collect MTB cells (Wolfe et al. 1987; Li et al. 2010b) and examined with TEM observations. Approximately $5 \mu \mathrm{l}$ purified cells from the bottom of tube was deposited on a carbon-coated copper TEM grid and the grid was washed with Milli-Q water, then dried in air. The morphology of cells and the magnetosomes was investigated using a Hitachi HT7700 TEM operating at $100 \mathrm{kV}$. Cell size and cell diameter, and the length and width of magnetosome particles were measured from the TEM images of MTB. The detailed morphology, and the composition and crystal structure of magnetosomes were examined using high-resolution transmission electron microscopy (HRTEM; JEM-2100, JEOL) in a system equipped with energy dispersive X-ray spectroscopy (EDXS) operating at $200 \mathrm{kV}$.

\subsection{DNA extraction, 16S rRNA gene sequencing, and dataset analysis}

Genomic DNA was extracted from $5 \mathrm{~g}$ of sediments following the modified methods described by Kvist (Kvist et al. 2007). The genomic DNA was purified using the Wizard ${ }^{\circledR}$ DNA Clean-up System (Promega), following the manufacturer's protocol. The hypervariable region V3-V4 of the bacterial 16S rRNA gene was amplified using the bar-coded universal primers 338F (5'-ACTCCTACGGGAGGCAGCA-3') and 806R (5'-GGACTACHVGGGTWTCTAAT-3'). Paired-end reads were generated using the Illumina MiSeq platform, and were overlapped using FLASH (Fast Length Adjustment of Short reads, version 1.2.11) (Magoč and Salzberg 2011). High quality reads were clustered into OTUs (operational taxonomic units) using UPARSE (Edgar 2013) with a 97\% threshold, and UCHIME (version 4.2.40) was used to filter and remove chimeras 
(Edgar et al. 2011). MTB were identified using BLAST and the NCBI nt database. The alignment of MTB sequences was performed using CLUSTAL X (version 2.0) with manual correction (Larkin et al. 2007). A phylogenetic tree was constructed using MEGA (version 7.0.26) software via the neighbor-joining method (Saitou and Nei 1987). Bootstrap values were calculated based on 1000 replicates.

\section{RESULT}

\subsection{Sampling stations and the distribution of MTB in sediments of the Caroline Seamount}

The Caroline Seamount (CM4) is located approximately $129 \mathrm{~km}$ to the southeast of the Kexue Seamount, and they are separated by the Mariana Trench (Fig.1). Optical microscopy observations were performed immediately following magnetic enrichment of MTB. Living MTB cells were observed in samples from 12 of the 13 stations, and were present at an average abundance of $1.5 \times 10^{4}$ ind. $/ \mathrm{dm}^{3}\left(1.1-43.7 \times 10^{3}\right.$ ind./ $\left.\mathrm{dm}^{3}\right)$, with magnetotactic cocci being the dominant morphotype. However, no live MTB were observed in samples from the deepest station CM4-00, which was far from the summit area of the Caroline Seamount at a depth of $2805 \mathrm{~m}$ (Fig.2a).

MTB were mainly detected on the north, south, and east slopes of the Caroline Seamount (Fig.2a). The average abundance of MTB in the northern region (including stations CM4-7, CM4-6, CM4-6-1, and CM4-5) was $2.4 \times 10^{4}$ ind./ $/ \mathrm{dm}^{3}$, and was greater than in the southern $(1.6 \times$

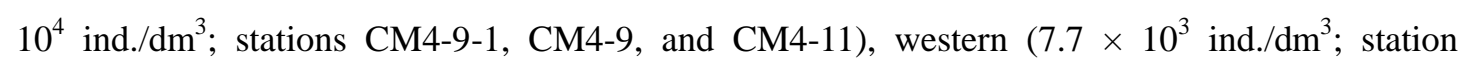
CM4-8 only), and eastern (7.3 × $10^{3}$ ind./dm ${ }^{3}$; stations CM4-2-1, CM4-10, CM4-2, and CM4-4) regions. The vertical distribution of MTB abundance was illustrated by three groups defined according to the water depth and the dissolved oxygen in the seawater (Fig.2b). Above the $200 \mathrm{~m}$ layer (near the euphotic layer), sediments were sampled at station CM4-9-1 only (90 m depth), which had a MTB abundance of $1.4 \times 10^{4}$ ind./ $/ \mathrm{dm}^{3}$. In the $200-1000 \mathrm{~m}$ layer (twilight zone) there were seven stations that had an average MTB abundance of $1.5 \times 10^{4} \mathrm{ind} . / \mathrm{dm}^{3}$. In this layer the number of MTB at the various stations decreased slightly with increasing water depth. Below 1 $000 \mathrm{~m}$ (the bathypelagic layer) there were four stations that had an average MTB abundance of 1.5 $\times 10^{4}$ ind. $/ \mathrm{dm}^{3}$. In this layer, the abundance tended to increase with increasing water depth, and the abundance was particularly high at $1545 \mathrm{~m}$ depth (station CM4-7). Nevertheless, the highest and lowest abundances of MTB both occurred at depths beyond $1000 \mathrm{~m}: 4.4 \times 10^{4}$ ind./. $\mathrm{dm}^{3}$ at station 
CM4-7 (1 $545 \mathrm{~m}$ depth) and $1.1 \times 10^{3}$ ind./. $\mathrm{dm}^{3}$ at station CM4-11 (1 $423 \mathrm{~m}$ depth). The most abundant station CM4-7 is located in an oxic-anoxic transition region with a dissolved oxygen content of $3 \mathrm{mg} / \mathrm{L}$ (Fig.2b).
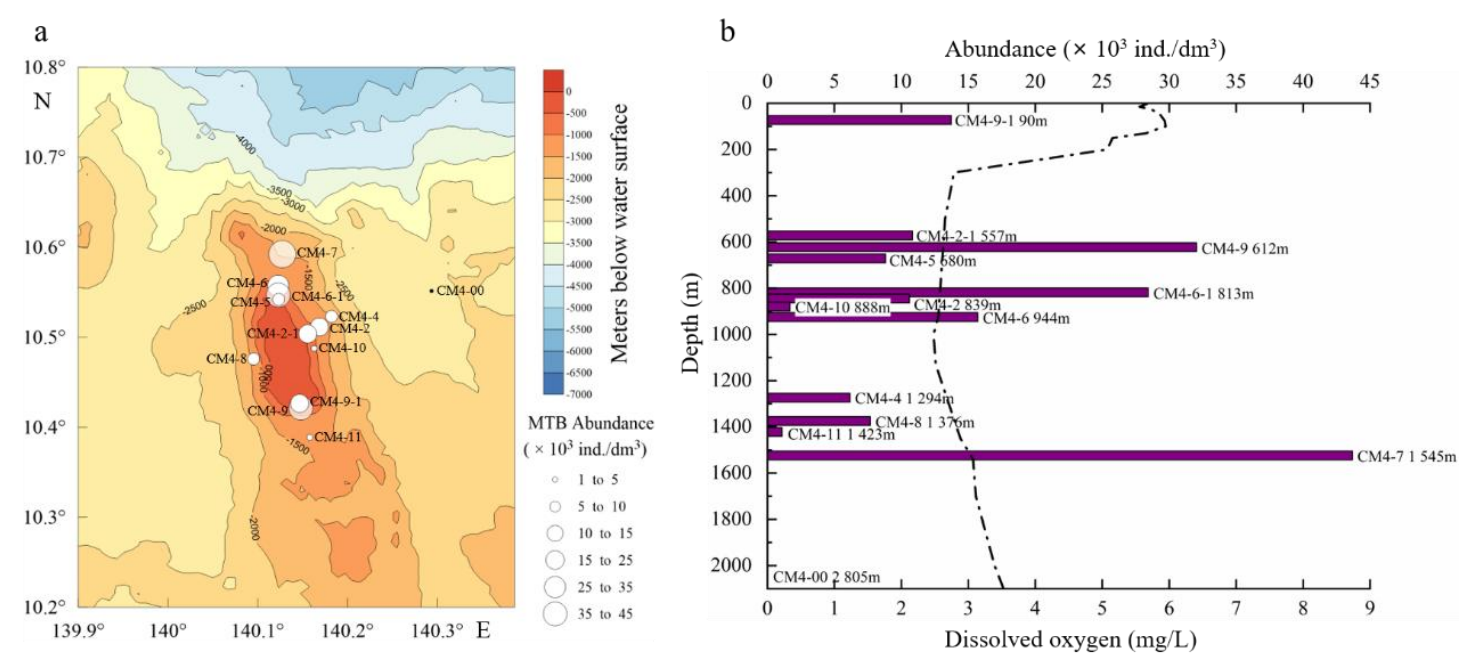

Fig.2 Distribution of MTB at the Caroline Seamount

a. Average abundance of MTB detected at 13 stations. The size of the white circles indicates the MTB abundance, and the black dot indicates that no live MTB were observed; b. Vertical distribution of MTB abundance. The dashed line indicates the dissolved oxygen concentration in the water column.

\subsection{Diverse morphologies of MTB and characterization of magnetosomes}

Using TEM, diverse morphologies of MTB (coccus, vibrio, and spirillum) were observed (Fig.3) in the sediments of merely six stations of the Caroline Seamount in situ (Table S1), but magnetotactic cocci were the dominant morphology. Four types of MTB were categorized based on characteristics including the morphology of cells, the flagellar apparatus, and the magnetosome shapes. The first and most abundant type was typical cocci (Fig.3a1) having an average diameter of $1.5 \pm 0.4 \mu \mathrm{m}(\mathrm{n}=38)$; one of these appeared to have peritrichous flagella (approximately 35$)$ that were distributed over the cell (Fig.3a1). The second type was drop-shaped cocci that had numerous flagella in a tuft at one end of the cell (Fig.3b1). They had an average cell size of $2.1 \pm$ $0.3 \times 1.7 \pm 0.3 \mu \mathrm{m}(\mathrm{n}=11)$, and the flagella length varied from 5.3 to $26.2 \mu \mathrm{m}$, which exceeded the cell length by a factor of 5.7 in average (the longest flagellum is 9.8 times larger than the corresponding length of the cell). Magnetotactic spirillum (Fig.3c) and vibrio (Fig.3d) cells comprised the other two MTB categories, having cell sizes of $4.2 \times 0.4 \mu \mathrm{m}(\mathrm{n}=1)$ and $2.0 \times 0.4$ $\mu \mathrm{m}(\mathrm{n}=1)$, respectively. 


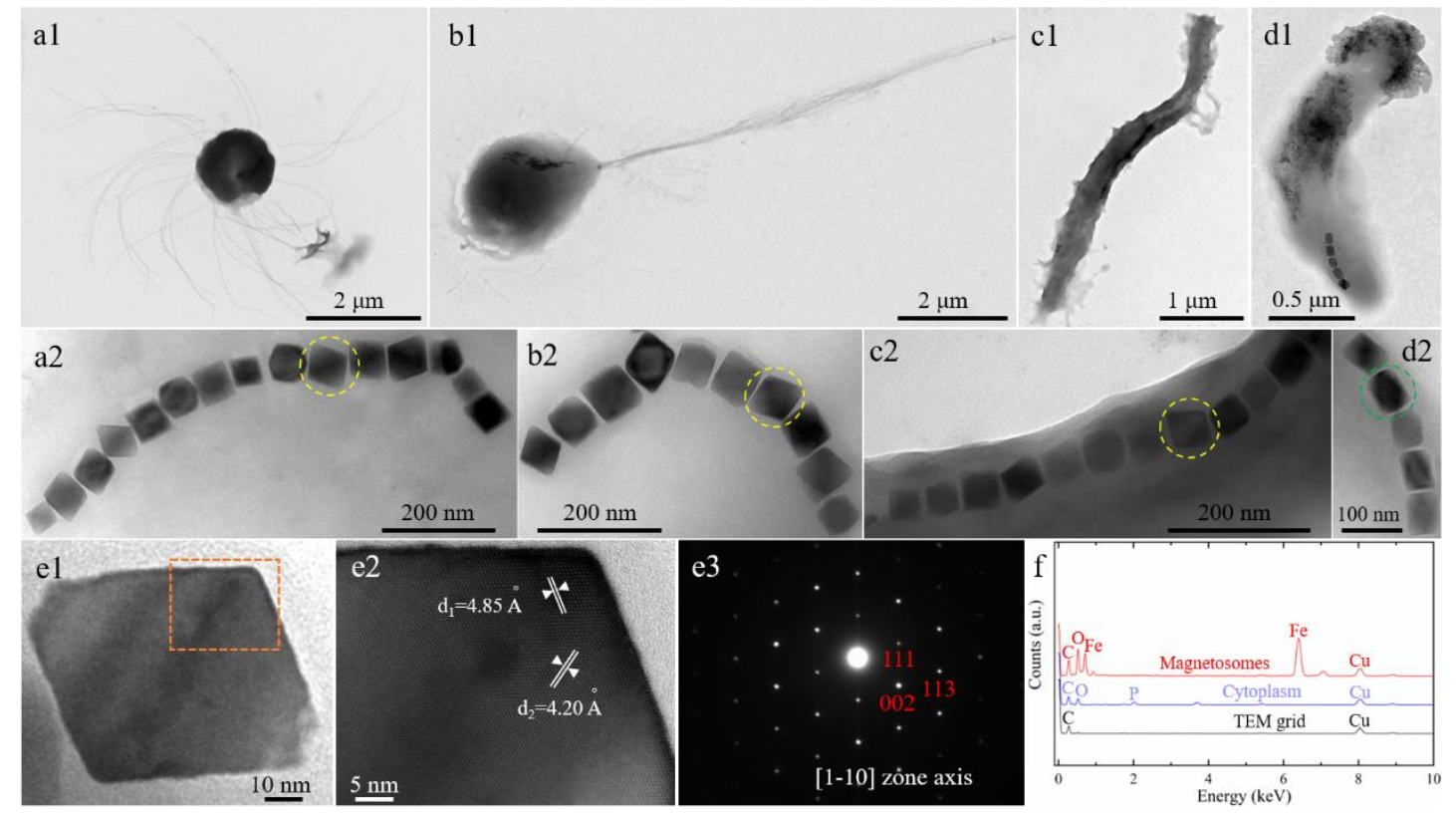

Fig.3 Morphology of the magnetotactic bacteria and characteristics of magnetosomes

Typical cocci (a1), drop-shaped cocci (b1), spirillum (c1), and vibrio (d1) MTB observed in sediment samples from the Caroline Seamount. Features of the magnetosomes of the typical cocci (a2), drop-shaped cocci (b2), spirillum (c2), and vibrio (d2) MTB. Diverse morphologies of magnetosomes (a2-d2) included octahedral (yellow circles) and prismatic (green circles) crystals. TEM image of the octahedral magnetosome (e1). Enlarged image (e2) of the orange framed area of e1. The corresponding indexed Fast Fourier transform (FFT) pattern of the octahedral magnetosome particle (e3). EDXS analysis of magnetosomes (f). Scale bars are $2 \mu \mathrm{m}$ in a1 and b1; $1 \mu \mathrm{m}$ in $\mathrm{c} 1 ; 0.5$ $\mu \mathrm{m}$ in $\mathrm{d} 1 ; 200 \mathrm{~nm}$ in $\mathrm{a} 2, \mathrm{~b} 2$, and $\mathrm{c} 2 ; 100 \mathrm{~nm}$ in $\mathrm{d} 2 ; 10 \mathrm{~nm}$ in $\mathrm{e} 1$; and $5 \mathrm{~nm}$ in $\mathrm{e} 2$.

The magnetosomes within the MTB cells were all organized in chains having diverse arrangements. Most magnetotactic cocci biomineralized a single magnetosome chain in each cell (Fig.4a), while others biosynthesized two parallel (Fig.4b) or intertwining (Fig.4c) magnetosome chains. Three chain forms were observed in some cocci (Fig.4d). In the spirillum and vibrio, the magnetosome particles were arranged as a single chain along the long axis (Fig.3c1 and 3d1).

Two main morphologies of magnetosome were observed including the octahedral and prismatic shapes (Fig.3a2-d2). The average sizes of the octahedral magnetosomes in these three types of MTB were $57.3 \pm 11.4 \times 53.9 \pm 10.4 \mathrm{~nm}(\mathrm{n}=554), 60.3 \pm 12.9 \times 56.6 \pm 12.4 \mathrm{~nm}(\mathrm{n}=204)$ and $48.1 \pm 4.8 \times 45.3 \pm 4.3 \mathrm{~nm}(\mathrm{n}=22)$, respectively, and the average width/length ratio of these MTB types was $0.94 \pm 0.04(\mathrm{n}=780)$. The magnetosome crystals in the vibrio cells were predominantly elongated prismatic, and were $66.9 \pm 3.9 \times 53.0 \pm 3.2 \mathrm{~nm}$ in size and had a 
width/length ratio of $0.79 \pm 0.01(\mathrm{n}=5)$. HRTEM and EDXS analysis indicated that all magnetosomes types analyzed were composed of magnetite $\left(\mathrm{Fe}_{3} \mathrm{O}_{4}\right)$.

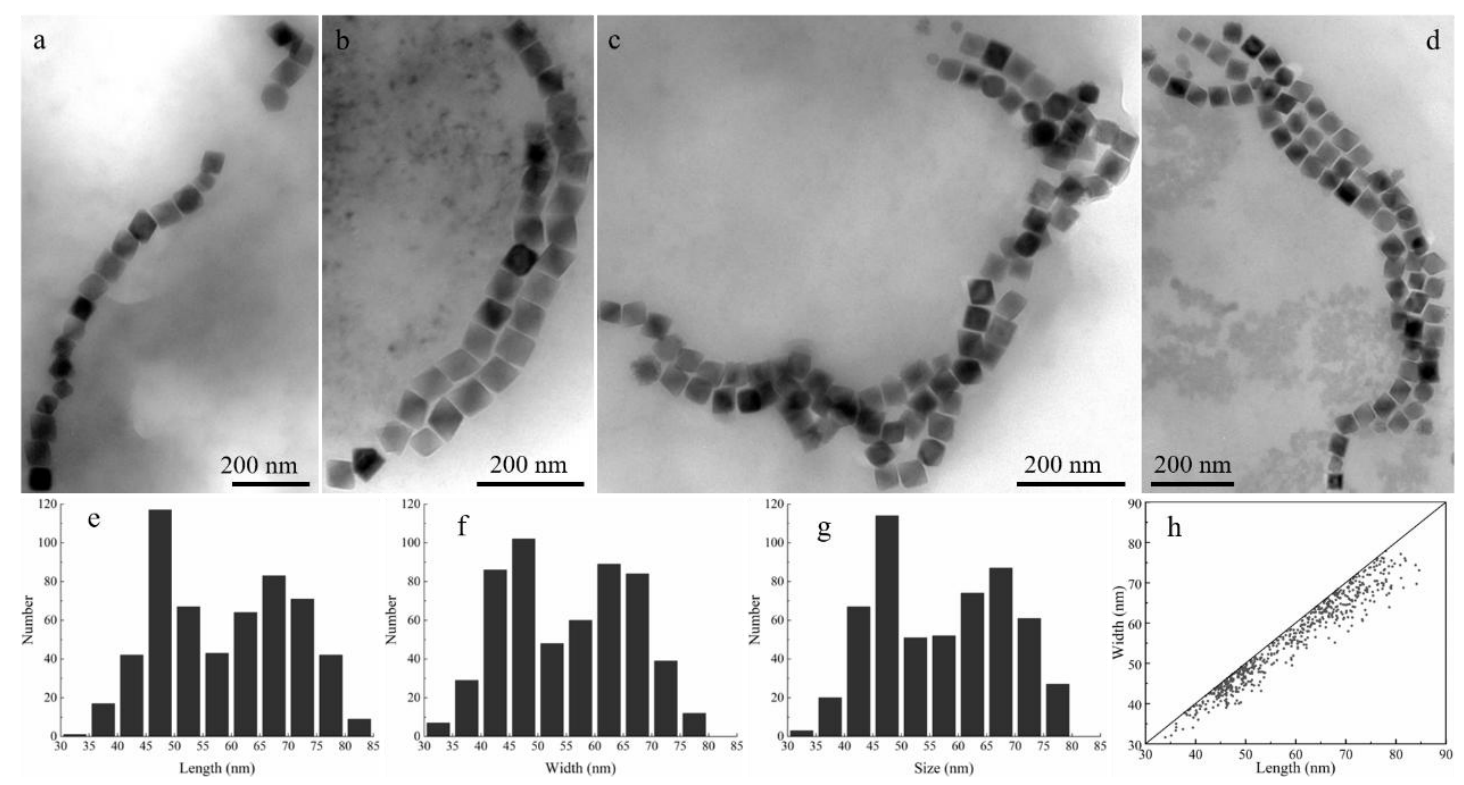

Fig.4 Magnetosome chain configurations and the features of magnetosomes in magnetotactic cocci

Diverse magnetosome chain configurations were observed among the magnetotactic cocci, including single (a), two parallel (b), two twining (c), and three (d) chains. Histograms of the distributions of the length (e), width (f), and size (g) of octahedral magnetosomes, and (h) a dot plot distribution of the shape factor. Scale bars are $200 \mathrm{~nm}$ in a, b, c, and d.

\subsection{Phylogenetic diversity of MTB in sediments of the Caroline Seamount}

Sufficient DNA for analysis was extracted from sediments from nine stations (CM4-2, CM4-5, CM4-6, CM4-7, CM4-8, CM4-9, CM4-10, CM4-11, and CM4-00; depth range: 612-2 $805 \mathrm{~m})$. High-quality 16S rRNA gene sequences for each station ranging from 35523 to 46743 were retrieved from the raw data. The rarefaction curves indicated that the sequencing depths were sufficient, and the sequencing results were reliable. These reads were classified into 2 184-3 301 OTUs, based on a threshold of $97 \%$ sequence similarity (Tindall et al. 2010). In total, 41 OTUs (2 702 reads) were affiliated with MTB, based on a BLAST search of the NCBI nt database (Table 1 and Fig.5). Among these putative MTB sequences, 17-32 OTUs of putative MTB were detected at each station (Fig.6a). The largest number of putative MTB OTUs (32) occurred at $1376 \mathrm{~m}$ depth at station CM4-8, while the lowest value (17) occurred at $680 \mathrm{~m}$ depth at station CM4-5. The maximum number of MTB reads (557) was found at station CM4-8 (1 $376 \mathrm{~m}$ depth), and the next greatest number of reads (541) was found at station CM4-9 (612 m depth). The lowest number of 
reads (165) was found at station CM4-6 (944 m depth), and the second lowest number (172) was found at station CM4-00 (2 $805 \mathrm{~m}$ depth) (Fig.6b).

Table 1 MTB OTUs, reads, and abundances at nine stations on the Caroline Seamount

MTB OTUs and reads were determined using next generation sequencing. The MTB abundance $\left(\times 10^{3}\right.$ ind./ $\left./ \mathrm{dm}^{3}\right)$ was calculated based on microscopy observations of live MTB.

\begin{tabular}{|c|c|c|c|c|c|c|c|c|c|c|}
\hline Station & $\begin{array}{c}\text { Depth } \\
(\mathbf{m})\end{array}$ & $\begin{array}{c}\text { Longitude } \\
\left(140^{\circ} \mathrm{E}\right)\end{array}$ & $\begin{array}{l}\text { Latitude } \\
\left(10^{\circ} \mathrm{N}\right)\end{array}$ & $\begin{array}{l}\text { MTB } \\
\text { OTUs }\end{array}$ & $\begin{array}{c}\text { Bacteria } \\
\text { OTUs }\end{array}$ & $\begin{array}{c}\text { Percentage of } \\
\text { MTB OTUs (\%) }\end{array}$ & $\begin{array}{l}\text { MTB } \\
\text { reads }\end{array}$ & $\begin{array}{c}\text { Bacteria } \\
\text { reads }\end{array}$ & $\begin{array}{c}\text { Percentage of } \\
\text { MTB reads (\%) }\end{array}$ & $\begin{array}{l}\text { MTB abundance } \\
\left(\times 10^{3} \text { ind./dm }\right)^{3}\end{array}$ \\
\hline CM4-9 & 612 & $08^{\prime} 53^{\prime \prime}$ & $25^{\prime} 16^{\prime \prime}$ & 23 & 3084 & 0.75 & 541 & 41333 & 1.31 & 32.0 \\
\hline CM4-5 & 680 & $07^{\prime} 24^{\prime \prime}$ & $32^{\prime} 31^{\prime \prime}$ & 17 & 2726 & 0.62 & 221 & 41068 & 0.54 & 8.8 \\
\hline CM4-2 & 839 & $10^{\prime} 07^{\prime \prime}$ & $30^{\prime} 41^{\prime \prime}$ & 19 & 2973 & 0.64 & 266 & 43044 & 0.62 & 10.6 \\
\hline CM4-10 & 888 & $09^{\prime} 47^{\prime \prime}$ & $29^{\prime} 15^{\prime \prime}$ & 23 & 2747 & 0.84 & 280 & 37543 & 0.75 & 1.7 \\
\hline CM4-6 & 944 & $07^{\prime} 23^{\prime \prime}$ & $33^{\prime} 26^{\prime \prime}$ & 23 & 2970 & 0.77 & 165 & 45159 & 0.37 & 15.7 \\
\hline CM4-8 & 1376 & $05^{\prime} 44^{\prime \prime}$ & $28^{\prime} 32^{\prime \prime}$ & 32 & 3301 & 0.97 & 557 & 42631 & 1.31 & 7.7 \\
\hline CM4-11 & 1423 & $09^{\prime} 24^{\prime \prime}$ & $23^{\prime} 19^{\prime \prime}$ & 19 & 2496 & 0.76 & 269 & 35523 & 0.76 & 1.1 \\
\hline CM4-7 & 1545 & $07^{\prime} 39^{\prime \prime}$ & $35^{\prime} 32^{\prime \prime}$ & 22 & 2943 & 0.75 & 231 & 38683 & 0.6 & 43.7 \\
\hline CM4-00 & 2805 & $17^{\prime} 38^{\prime \prime}$ & $33^{\prime} 04^{\prime \prime}$ & 24 & 2184 & 1.1 & 172 & 46743 & 0.37 & - \\
\hline
\end{tabular}

All the putative MTB OTUs were related to the Alphaproteobacteria, except for OTU4156 and OTU1871 (Fig.5). Based on the most up-to-date NCBI taxonomic database, OTU4156 (four reads) and OTU1871 (seven reads) were the closest to uncultured Magnetococcus clone OTU9 (MF099880) belonging to "Candidatus Etaproteobacteria", and "Candidatus" Magnetoovum mohavensis strain LO-1 (GU979422) belonging to the phylum Nitrospirae, respectively. Among the 39 OTUs affiliated to the Alphaproteobacteria, 24 were closest to Magnetospira sp. QH-2 (EU675666), with seven of these closest to Magnetospira thiophila MMS-1 (EU861390), four closest to uncultured Magnetospira clone (KP183009), two closest to uncultured Magnetospirillum clones (HQ222269 and HQ154657), and two closest to Magnetovibrio blakemorei MV-1 (L06455). 


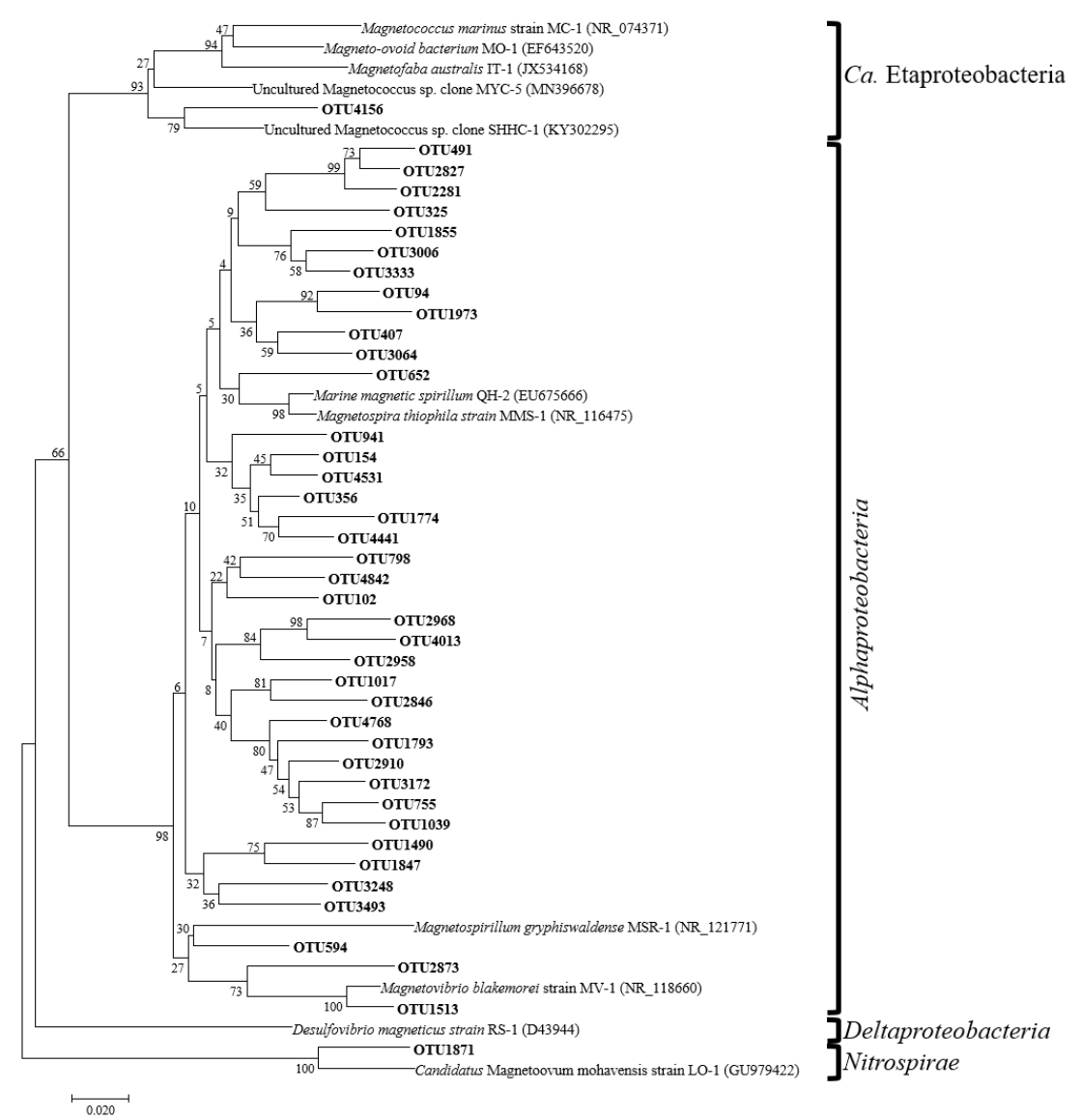

Fig.5 Neighbor-joining phylogenetic tree showing the relationship of the putative 41 MTB OTUs from the Caroline Seamount to the closest database matches.

The tree was constructed using MEGA 7, based on an approximately 419 bp sequence of the 16S rRNA gene. The GenBank accession numbers were indicated in parentheses. The bootstrap values were calculated based on 1000 replicates. Bar indicates $2 \%$ sequence divergence.

Remarkably, the most common five OTUs, including OTU102 (718 reads), OTU154 (432 reads), OTU356 (190 reads), OTU94 (155 reads), and OTU594 (139 reads), accounted for 60.5\% (1 623 reads) of the total MTB reads. They all belonged to the genus Magnetospira, and were distributed among almost all the nine stations on the Caroline Seamount; the exception was OTU594, which was not detected at station CM4-7 (Fig.6c). 


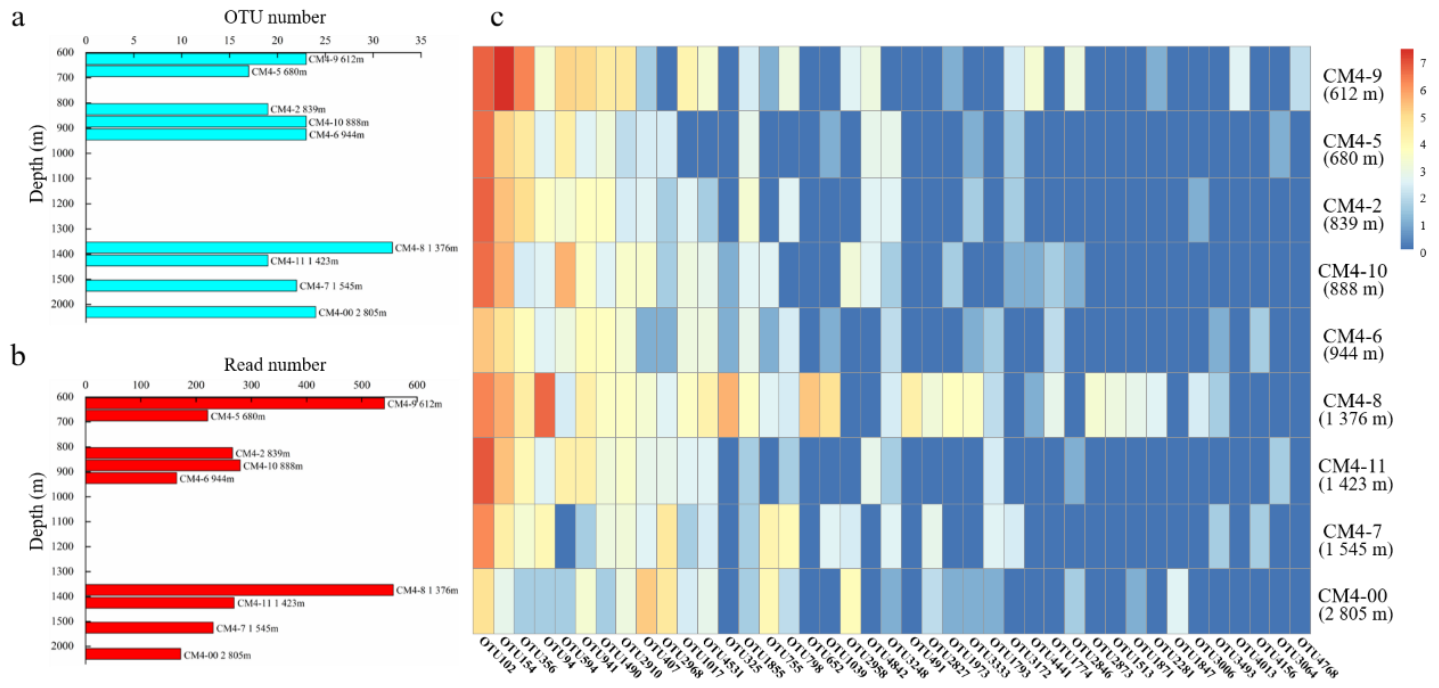

Fig.6 Vertical distribution of MTB OTUs (a) and MTB reads (b), and a heatmap of the various compositions of MTB OTUs and reads at the nine stations

The MTB reads data were transformed logarithmically.

\section{DISCUSSION}

Based on direct microscope counts of MTB, their abundance in sediments of the Caroline Seamount averaged approximately $1.5 \times 10^{4}$ ind. $/ \mathrm{dm}^{3}$, which is higher than the average abundance in sediments of the continental shelf of the Yellow Sea $\left(290\right.$ ind. $/ \mathrm{dm}^{3}$ in summer; 130 ind. $/ \mathrm{dm}^{3}$ in winter) (Xu et al. 2018), but is orders of magnitude lower than the abundance of MTB at a seamount station $\left(4 \times 10^{5} \mathrm{ind} . / \mathrm{dm}^{3}\right.$ at site 1726$)$ in the South Atlantic Ocean (Petermann and Bleil 1993), in the Mediterranean Sea $\left(10^{5}-10^{6}\right.$ ind./ $\mathrm{dm}^{3}$ in summer) (Lefèvre et al. 2007), and in intertidal sediments of the Yellow Sea including at Lake Yuehu $\left(10^{6}-10^{7}\right.$ ind./ $\left./ \mathrm{dm}^{3}\right)($ Du et al. 2017) and Xiaoshi Island $\left(10^{7}-10^{8}\right.$ ind./ $\left.\mathrm{dm}^{3}\right)($ Chen et al. 2015). Notably, the MTB abundance at the Caroline Seamount was much higher than that at the Kexue Seamount $\left(54.6\right.$ ind./ $\left.\mathrm{dm}^{3}\right)$; these seamounts are adjacent to each other but separated by the Mariana Trench (Liu et al. 2017). Previous studies have suggested that many MTB populations have the ability to fix nitrogen, as they contain the full suite of nif genes in their genomes (Bazylinski and Blakemore 1983; Bazylinski et al. 2000; Schübbe et al. 2009; Bazylinski et al. 2013b). Recently, the nap, nar, and nir genes were found in Mcas genome (strain MYR-1, Nitrospirae phylum), which also implied that the magnetotactic Mcas strain has the potential ability to transform nitrate to $\mathrm{N}_{2} / \mathrm{NH}_{4}{ }^{+}$(Lin et al. 2014; Li et al. 2020c). Investigation of the distribution of nutrients in the euphotic zone (0-200 
m) at the Kexue (also designated M2) and Caroline (also designated C4) seamounts has recently indicated that nitrogen limitation at the Caroline Seamount $(\mathrm{N}: \mathrm{P}=13.5: 1)$ was less than at the Kexue Seamount ( $\mathrm{N}: \mathrm{P}=3.7: 1)$ (Ma et al. 2019). Thus, it is possible that the greater abundance of MTB at the Caroline Seamount contributes to this phenomenon, although further investigation of this is required.

Based on high-throughput 16S rRNA sequencing analyses, the dominant group of MTB at the Caroline Seamount was related to the Magnetospira, while magnetotactic cocci were the most abundant group in the intertidal sediments of Yuehu Lake (Zhang et al. 2019), and Nitrospirae MTB dominated in sediments of the Yellow Sea continental shelf (Xu et al. 2018). Although MTB OTUs affiliated to Magnetospira were the dominant groups at both the Kexue and Caroline seamounts, the communities of MTB in the sediments of the Caroline Seamount were more complex and diverse (Fig.7a). At the Kexue Seamount, Liu et al. (2017) detected 21 putative MTB OTUs (1 130 reads), while 41 MTB OTUs (2 702 reads) were found at the Caroline Seamount. The numbers of both MTB OTUs and reads at the Caroline Seamount were approximately twice that at the Kexue Seamount. In addition, the MTB OTUs affiliated with Etaproteobacteria and Nitrospirae were only detected at the Caroline Seamount. Up to now, Nitrospirae MTB biomineralize bullet-shaped magnetosomes, but those characteristic particles were not examined within MTB individuals by TEM analyses unfortunately. It might result from the low number of Nitrospirae MTB cells dwelled in the seamount habitat, which made it difficult to detect them though they were present at the Caroline Seamount actually. Comparison of the mean Chao, Shannon, and Simpson diversity indices for MTB from different habitats is shown in Table S2. The data suggest that the diversity of MTB at the Caroline Seamount was richer than at the Kexue Seamount, but lower than in the Yellow Sea and Yuehu Lake. Discrepancies in the community compositions of MTB may be influenced by the environmental characteristics in the various habitats. Biogeographic studies have suggested that environments heterogeneous for factors including salinity, temperature, nitrate, or sulfur compounds may be responsible for differences in the abundance or community composition of MTB (Martins et al. 2009; Postec et al. 2011; Lin et al. 2012b; Martins et al. 2012; Lin et al. 2013; Silva et al. 2020).

Although the diversity of MTB at the Caroline Seamount was richer than at the Kexue Seamount, 11 MTB OTUs were shared between the two seamounts (Fig.7b), accounting for $26.8 \%$ 
and $52.4 \%$ of the total MTB OTUs at these two seamounts, respectively. The reads of shared MTB OTUs accounted for 63.6\% (1 719 reads) and 54.8\% (619 reads) at the Caroline and Kexue seamounts, respectively. More interestingly, among 11 shared MTB OTUs, four OTUs are the most common for Caroline Seamount (OTU102, 154, 356 and 594) which correspond to OTU1697 (third most common), 2037 (most common), 684 (thirteenth most common) and 675 (fifth most common) for Kexue Seamount, respectively. This finding suggests that the dominant MTB populations were consistent between the two seamounts. In addition, the phylogenetic analyses showed that most of the shared MTB OTUs were clustered into a single large branch in the Alphaproteobacteria. Notably, these two seamounts are both shallow (Genin 2004), with the distance from summit to the sea surface being $<200 \mathrm{~m}$, and the sediment at both is mainly composed of coral and foraminiferan sands (Fig.S1; Liu et al. 2017). The similar geological properties and hydrological conditions of the seamounts may be significant in determining the occurrence of MTB. Therefore, it is reasonable to infer that there is population connectivity between these two seamounts, at least for the MTB community.

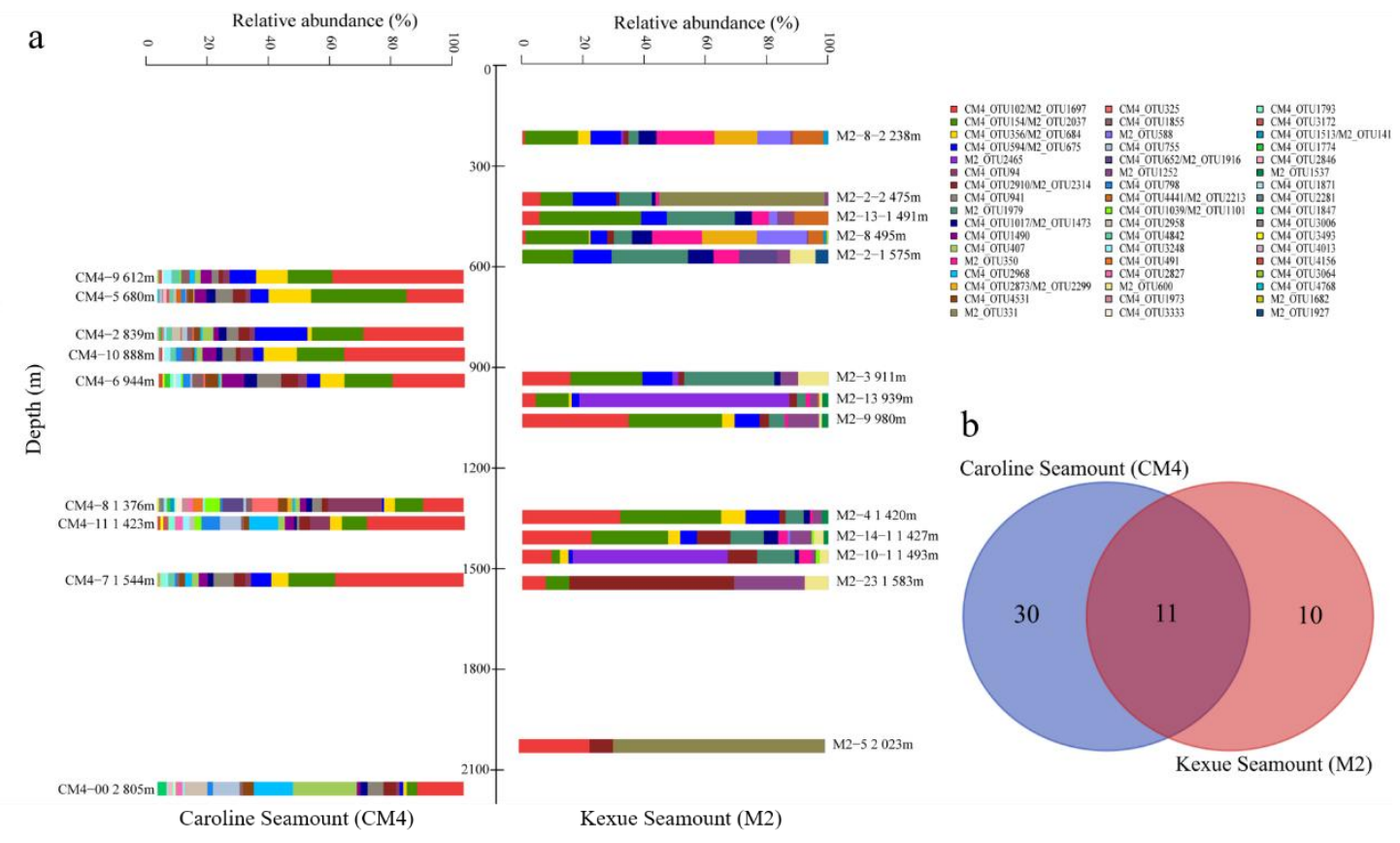

Fig.7 Comparison of MTB communities from the Caroline (CM4) and Kexue (M2) seamounts

a. The relative abundance of MTB reads from diverse stations at the two seamounts; b. Overlap in the composition of MTB OTUs at the two seamounts.

TEM observations showed that diverse morphotypes of MTB, including cocci, vibrio, and 
spirillum forms, were present in enrichments of the samples collected from the Caroline Seamount. Magnetotactic cocci were the dominant morphology, which was a finding consistent with previous reports (Spring et al. 1998; Flies et al. 2005b; Lin et al. 2009; Lin and Pan 2009; Du et al. 2017; Liu et al. 2017; Xu et al. 2018). Based on previous studies, most magnetotactic cocci affiliated to the Proteobacteria phylum have two tufts of flagella. For example, both Magnetococcus marinus MC-1 (Bazylinski et al. 2013b) and magnetotactic ovoid strain MO-1 (Zhang et al. 2012) have two sheathed bundles of flagella, while magnetotactic cocci strains IT-1 (Araujo et al. 2016), SHHC-1 (Zhang et al. 2017), and QHL (Pan et al. 2008) have two bundles of lophotrichous flagella lacking a sheath. At the Kexue Seamount, one type of magnetotactic cocci having two bundles of flagella was found, with the 19 flagella in each bundle arranged in a 3:4:5:4:3 array (Liu et al. 2017); this is unlike MO-1, which has only seven flagella (Ruan et al. 2012). It has been speculated that the more complex flagellar assembly is the result of adaptation to the seamount environment (Liu et al. 2017). In the present study we observed magnetotactic cocci having putative peritrichous flagella (It remains possible that the spread of a single bundle of flagella may have given the appearance of peritrichous flagella) (Fig.3a1), and drop-shaped cocci having a single bundle of flagella (Fig.3b1). MTB affiliated to the Nitrospirae phylum, including the large rod "Candidatus Magnetobacterium casensis" (Lin et al. 2014), the watermelon-shaped MWB-1 (Lin et al. 2012a), and the large ovoid LO-1 (Lefèvre et al. 2011a) have been reported to have single bundles of flagella. Magnetotactic cocci having two bundles of flagella have been reported as one of the fastest natural micro-swimmers (Bente et al. 2020). These findings imply that having a single bundle of flagella is sufficient to enable motility of MTB at the Caroline Seamount. During sampling of sediments from this seamount using the ROV "Faxian", the occurrence of strong ocean bottom currents was evident, and these may cause the surface sediment to drift. In addition, seamount slope topography is known to affect the spatial distribution of sediments. Thus, it is likely that the MTB inhabiting the Caroline Seamount surface sediment can move easily because of ocean currents and the seamount slope, which could result in the evolution of single bundle of flagella.

Although the properties of magnetosomes are controlled by genes in the MTB, there are some evidences that they can be influenced by environmental conditions (see the recent review by Moisescu et al. 2014). For example, Fe uptake rates and $\mathrm{pH}$ seem to affect the size and 
morphology of magnetite crystals in the type strain of Magnetospirillum gryphiswaldense MSR-1 (Faivre et al. 2008; Moisescu et al. 2011), and the size of magnetosomes in M. magneticum strain AMB-1 varies with variations in the oxygen concentration or magnetic field intensity (Wang et al. 2008; Popa et al. 2009; Li and Pan 2012; Moisescu et al. 2014). In culture, Desulfamplus magnetovallimortis strain BW-1 synthesizes bullet-shaped magnetite magnetosomes in the presence of $<0.3 \mathrm{mM}$ sulfide, and roughly rectangular greigite magnetosomes when the sulfide concentration is $>0.3 \mathrm{mM}$ (Lefèvre et al. 2011b). In the present study, octahedral magnetite magnetosomes were found to occur in magnetotactic cocci and the magnetotactic spirillum (Fig.3) And among living MTB reported elsewhere, only few appear to be able to synthesize octahedral magnetite magnetosomes, including Magnetofaba australis IT-1, magnetotactic coccus strains SHHC-1 and MYC-5, and an unclassified magnetotactic spirillum from a pond (Vali et al. 1987; Araujo et al. 2016; Zhang et al. 2017; Liu et al. 2020) Intriguingly, the dominant magnetotactic cocci at the Kexue Seamount without growing in the bottles also synthesized octahedral magnetite crystals (Liu et al. 2017). It is notable that both the IT-1 and SHHC-1 strains appear to have a greater adaptability to changing environments, based on genomic data for IT-1 and the co-occurrence of various magnetosome forms in individual SHHC-1 cells (Araujo et al. 2016; Zhang et al. 2017). As noted above, the sediments at both seamounts are mainly composed of unconsolidated coral and foraminiferan sands (Fig.S1), which can easily drift in ocean currents. Thus, it is possible that unstable habitats result in an increase in the biomineralization of octahedral magnetosomes by MTB. Further research should be undertaken to test this hypothesis. In contrast, octahedral magnetofossils seem to be common and the main magnetosome type in deep sea sediments (Vali et al. 1987; Yamazaki and Kawahata 1998; Dong et al. 2016; Yamazaki et al. 2019; He and Pan 2020; Li et al. 2020d) and especially red clay (Yamazaki and Shimono 2013; Usui et al. 2017). In red clay, octahedral magnetofossils were found to be associated with high oxygen concentrations, inferring that some MTB species that synthesize octahedral magnetosomes may be oxygen tolerant (Yamazaki et al. 2019). Therefore, the MTB living in unstable seamount sediments may be subject to high oxygen concentrations, leading to the domination of octahedral magnetosomes in some MTB species.

\section{CONCLUSION}

In this study we described the diversity, characteristics, and distribution of MTB from the 
Caroline Seamount (CM4). Based on TEM observations, magnetotactic cocci were the dominant morphotype. Among the typical MTB cocci, one type appeared to have peritrichous flagella (approximately 35); the other type of coccoid cells showed drop-shaped, and had a single bundle of flagella approximately a factor of 5.7 longer than the cell diameter in average. The dominant magnetosome morphology biomineralized in most MTB individuals with octahedral crystal habit; this study is the first to report the occurrence of octahedral magnetite particles among the diverse species of MTB living in the same seamount habitat. It was inferred that the biomineralization of magnetosome magnetite was related to both the species and environmental parameters. High-throughput 16S rRNA sequencing identified 41 putative MTB OTUs belonging to two phyla, Proteobacteria and Nitrospirae. Comparison of MTB diversity between the Caroline and Kexue seamounts suggested that there is both commonality (indicating connectivity) and specificity in terms of the MTB populations on these two seamounts.

\section{DATA AVAILABILITY STATEMENT}

All data generated and/or analyzed during the study are available from the corresponding author on reasonable request.

\section{ACKNOWLEDGEMENT}

This study was financially supported by the National Natural Science Foundation of China (Nos. $41776130 \& 41776131)$, the National Natural Science Foundation of China-Shandong Joint Fund (U1706208), the Youth Talent Support Program of the Laboratory for Marine Ecology and Environmental Science, Pilot National Laboratory for Marine Science and Technology (Qingdao) (LMEES-YTSP-2018-01-07), and the Science \& Technology Basic Resources Investigation Program of China (2017FY100803). We thank the crew and captain of vessel Kexue, the ROV team for sediments sampling. We thank Liu Wei, Sun Yuanyuan at the IOCAS (Institute of Oceanology, Chinese Academy of Sciences) for assistance in TEM observations. We thank the engineer Mr. Tang Xu at the IGGCAS (Institute of Geology and Geophysics, Chinese Academy of Sciences) for assistance in TEM experiments.

\section{References}

Abreu F, Martins J L, Silveira T S, et al. 2007. 'Candidatus Magnetoglobus multicellularis', a multicellular, magnetotactic prokaryote from a hypersaline environment. International Journal of Systematic and Evolutionary Microbiology, 57(Pt 6): 1 318-1 322. https://doi.org/10.1099/ijs.0.64857-0

Amor M, Mathon F P, Monteil C L, et al. 2020. Iron- biomineralizing organelle in magnetotactic bacteria: function, 
synthesis and preservation in ancient rock samples. Environmental microbiology, 22(9): 3 611-3 632. https://doi.org/10.1111/1462-2920.15098

Araujo A C, Morillo V, Cypriano J, et al. 2016. Combined genomic and structural analyses of a cultured magnetotactic bacterium reveals its niche adaptation to a dynamic environment. BMC genomics, 17(Supplement 8): 726. https://doi.org/10.1186/s12864-016-3064-9

Bazylinski D A, Blakemore R P. 1983. Nitrogen fixation (acetylene reduction) in Aquaspirillum magnetotacticum. Current Microbiology, 9(6): 305-308. https://doi.org/10.1007/BF01588824

Bazylinski D A, Dean A J, Schüler D, et al. 2000. $\mathrm{N}_{2}$-dependent growth and nitrogenase activity in the metal-metabolizing bacteria, Geobacter and Magnetospirillum species. Environmental microbiology, 2(3): 266-273. https://doi.org/10.1046/j.1462-2920.2000.00096.x

Bazylinski D A, Frankel R B. 2004. Magnetosome formation in prokaryotes. Nature Reviews Microbiology, 2(3): 217-230. https://doi.org/10.1038/nrmicro842

Bazylinski D A, Lefèvre C T, Schüler D. 2013a. Magnetotactic Bacteria. In: Rosenberg E, Delong E, Lory S, et al. eds. The prokaryotes. Springer-Verlag, Berlin Heidelberg, pp 453-494. https://doi.org/10.1007/978-3-642-30141-4_74

Bazylinski D A, Williams T J, Lefevre C T, et al. 2013b. Magnetococcus marinus gen. nov., sp. nov., a marine, magnetotactic bacterium that represents a novel lineage (Magnetococcaceae fam. nov., Magnetococcales ord. nov.) at the base of the Alphaproteobacteria. International Journal of Systematic and Evolutionary Microbiology, 63(Pt 3): 801-808. https://doi.org/10.1099/ijs.0.038927-0

Bente K, Mohammadinejad S, Charsooghi M A, et al. 2020. High-speed motility originates from cooperatively pushing and pulling flagella bundles in bilophotrichous bacteria. eLife, 9. https://doi.org/10.7554/eLife.47551

Chen H, Li J, Xing X, et al. 2015. Unexpected diversity of magnetococci in intertidal sediments of Xiaoshi Island in the North Yellow Sea. Journal of Nanomaterials, 2015(902121). https://doi.org/10.1155/2015/902121

Dong Y, Li J, Zhang W, et al. 2016. The detection of magnetotactic bacteria in deep sea sediments from the east Pacific Manganese Nodule Province. Environmental Microbiology Reports, 8(2): 239-249. https://doi.org/10.1111/1758-2229.12374

Dower J, Freeland H, Juniper K. 1992. A strong biological response to oceanic flow past Cobb Seamount. Deep-Sea Research Part A-Oceanographic Research Papers, 39(7-8A): $1 \quad 139-1 \quad 145$. https://doi.org/10.1016/0198-0149(92)90061-W

Du H, Zhang R, Zhang W, et al. 2017. Characterization of uncultivated magnetotactic bacteria from the sediments of Yuehu Lake, China. Acta Oceanologica Sinica, 36(2): 94-104. https://doi.org/10.1007/s13131-017-0980-8

Edgar R C, Haas B J, Clemente J C, et al. 2011. UCHIME improves sensitivity and speed of chimera detection. Bioinformatics, 27(16): 2 194-2 200. https://doi.org/10.1093/bioinformatics/btr381

Edgar R C. 2013. UPARSE: highly accurate OTU sequences from microbial amplicon reads. Nature Methods, 10(10): 996-998. https://doi.org/10.1038/nmeth.2604

Faivre D, Menguy N, Pósfai M, et al. 2008. Environmental parameters affect the physical properties of fast-growing magnetosomes. American Mineralogist, 93(2-3): 463-469. https://doi.org/10.2138/am.2008.2678

Farina M, Debarros H L, Esquivel D M S, et al. 1983. Ultrastructure of a magnetotactic microorganism. Biology of the Cell, 48(1): 85-88.

Flies C B, Jonkers H M, de Beer D, et al. 2005a. Diversity and vertical distribution of magnetotactic bacteria along chemical gradients in freshwater microcosms. FEMS Microbiology Ecology, 52(2): 185-195. https://doi.org/10.1016/j.femsec.2004.11.006

Flies C B, Peplies J, Schüler D. 2005b. Combined approach for characterization of uncultivated magnetotactic bacteria from various aquatic environments. Applied and environmental microbiology, 71(5): 2 723-2 731. 
https://doi.org/10.1128/AEM.71.5.2723-2731.2005

Genin A, Boehlert G W. 1985. Dynamics of temperature and chlorophyll structures above a seamount: An oceanic experiment. Journal of Marine Research, 43(4): 907-924. https://doi.org/10.1357/002224085788453868

Genin A. 2004. Bio-physical coupling in the formation of zooplankton and fish aggregations over abrupt topographies. Journal of Marine Systems, 50(1-2): 3-20. https://doi.org/10.1016/j.jmarsys.2003.10.008

He K, Pan Y. 2020. Magnetofossil abundance and diversity as paleoenvironmental proxies: A case study from southwest Iberian margin sediments. Geophysical Research Letters, 47(8). https://doi.org/10.1029/2020gl087165

Hogg N G. 1973. On the stratified Taylor column. Journal of Fluid Mechanics, 58(3): 517-537. https://doi.org/10.1017/S0022112073002302

Isambert A, Menguy N, Larquet E, et al. 2007. Transmission electron microscopy study of magnetites in a freshwater population of magnetotactic bacteria. American Mineralogist, 92(4): 621-630. https://doi.org/10.2138/am.2007.2278

Ji B, Zhang S D, Zhang W J, et al. 2017. The chimeric nature of the genomes of marine magnetotactic coccoid-ovoid bacteria defines a novel group of Proteobacteria. Environmental microbiology, 19(3): 1 103-1 119. https://doi.org/10.1111/1462-2920.13637

Kolinko S, Jogler C, Katzmann E, et al. 2012. Single-cell analysis reveals a novel uncultivated magnetotactic bacterium within the candidate division OP3. Environmental microbiology, 14(7): 1 709-1 721. https://doi.org/10.1111/j.1462-2920.2011.02609.x

Kolinko S, Richter M, Glöckner F O, et al. 2016. Single-cell genomics of uncultivated deep-branching magnetotactic bacteria reveals a conserved set of magnetosome genes. Environmental microbiology, 18(1): 21-37. https://doi.org/10.1111/1462-2920.12907

Kozyaeva V V, Grouzdev D S, Dziuba M V, et al. 2017. Diversity of magnetotactic bacteria of the Moskva River. Microbiology, 86(1): 106-112. https://doi.org/10.1134/S0026261717010088

Kunze E, Sanford T B. 1996. Abyssal mixing: Where it is not. Journal of Physical Oceanography, 26(10): 2 286-2 296. https://doi.org/10.1175/1520-0485(1996)026<2286:AMWIIN>2.0.CO;2

Kvist T, Ahring B K, Lasken R S, et al. 2007. Specific single-cell isolation and genomic amplification of uncultured microorganisms. Applied microbiology and biotechnology, 74(4): 926-935. https://doi.org/10.1007/s00253-006-0725-7

Larkin M A, Blackshields G, Brown N P, et al. 2007. Clustal W and Clustal X version 2.0. Bioinformatics, 23(21): 2 947-2 948. https://doi.org/10.1093/bioinformatics/btm404

Lefèvre C, Bernadac A, Pradel N, et al. 2007. Characterization of Mediterranean magnetotactic bacteria. Journal of Ocean University of China, 6(4): 355-359. https://doi.org/10.1007/s11802-007-0355-4

Lefèvre C T, Bernadac A, Yu-Zhang K, et al. 2009. Isolation and characterization of a magnetotactic bacterial culture from the Mediterranean Sea. Environmental microbiology, 11(7): 1 646-1 657. https://doi.org/10.1111/j.1462-2920.2009.01887.x

Lefèvre C T, Frankel R B, Abreu F, et al. 2011a. Culture-independent characterization of a novel, uncultivated magnetotactic member of the Nitrospirae phylum. Environmental microbiology, 13(2): 538-549. https://doi.org/10.1111/j.1462-2920.2010.02361.x

Lefèvre C T, Menguy N, Abreu F, et al. 2011b. A cultured greigite-producing magnetotactic bacterium in a novel group of sulfate-reducing bacteria. Science, 334(6 063): 1 720-1 723. https://doi.org/10.1126/science.1212596

Lefèvre C T, Pósfai M, Abreu F, et al. 2011c. Morphological features of elongated-anisotropic magnetosome crystals in magnetotactic bacteria of the Nitrospirae phylum and the Deltaproteobacteria class. Earth and Planetary Science Letters, 312(1-2): 194-200. https://doi.org/10.1016/j.eps1.2011.10.003 
Lefèvre C T, Viloria N, Schmidt M L, et al. 2012. Novel magnetite-producing magnetotactic bacteria belonging to the Gammaproteobacteria. The ISME journal, 6(2): 440-450. https://doi.org/10.1038/ismej.2011.97

Lefèvre C T, Bazylinski D A. 2013. Ecology, diversity, and evolution of magnetotactic bacteria. Microbiology and Molecular Biology Reviews, 77(3): 497-526. https://doi.org/10.1128/MMBR.00021-13

Lefèvre C T, Wu L-F. 2013. Evolution of the bacterial organelle responsible for magnetotaxis. Trends in Microbiology, 21(10): 534-543. https://doi.org/10.1016/j.tim.2013.07.005

Li J, Pan Y, Liu Q, et al. 2010a. Biomineralization, crystallography and magnetic properties of bullet-shaped magnetite magnetosomes in giant rod magnetotactic bacteria. Earth and Planetary Science Letters, 293(3-4): 368-376. https://doi.org/10.1016/j.eps1.2010.03.007

Li J, Ge X, Zhang X, et al. 2010b. Recover vigorous cells of Magnetospirillum magneticum AMB-1 by capillary magnetic separation. Chinese Journal of Oceanology and Limnology, 28(4): 826-831. https://doi.org/10.1007/s00343-010-9068-4

Li J, Pan Y. 2012. Environmental factors affect magnetite magnetosome synthesis in Magnetospirillum magneticum AMB-1: Implications for biologically controlled mineralization. Geomicrobiology Journal, 29(4): 362-373. https://doi.org/10.1080/01490451.2011.565401

Li J, Menguy N, Gatel C, et al. 2015. Crystal growth of bullet-shaped magnetite in magnetotactic bacteria of the Nitrospirae phylum. J R Soc Interface, 12(103). https://doi.org/10.1098/rsif.2014.1288

Li J, Zhang H, Menguy N, et al. 2017. Single-cell resolution of uncultured magnetotactic bacteria via fluorescence-coupled electron microscopy. Applied and environmental microbiology, 83(12). https://doi.org/10.1128/AEM.00409-17

Li J, Zhang H, Liu P, et al. 2019. Phylogenetic and structural identification of a novel magnetotactic Deltaproteobacteria strain, WYHR-1, from a freshwater lake. Applied and environmental microbiology, 85(14). https://doi.org/10.1128/AEM.00731-19

Li J, Menguy N, Roberts A P, et al. 2020a. Bullet- shaped magnetite biomineralization within a magnetotactic Deltaproteobacterium: Implications for magnetofossil identification. Journal of Geophysical Research: Biogeosciences, 125(7). https://doi.org/10.1029/2020jg005680

Li J, Menguy N, Leroy E, et al. 2020b. Biomineralization and magnetism of uncultured magnetotactic coccus strain THC- 1 with non- chained magnetosomal magnetite nanoparticles. Journal of Geophysical Research: Solid Earth. https://doi.org/10.1029/2020jb020853

Li J, Liu P, Wang J, et al. 2020c. Magnetotaxis as an adaptation to enable bacterial shuttling of microbial sulfur and sulfur cycling across aquatic oxic- anoxic interfaces. Journal of Geophysical Research: Biogeosciences, 125(12). https://doi.org/10.1029/2020jg006012

Li J, Liu Y, Liu S, et al. 2020d. Classification of a complexly mixed magnetic mineral assemblage in Pacific Ocean surface sediment by electron microscopy and supervised magnetic unmixing. Frontiers in Earth Science, 8. https://doi.org/10.3389/feart.2020.609058

Lin W, Li J, Schüler D, et al. 2009. Diversity analysis of magnetotactic bacteria in Lake Miyun, northern China, by restriction fragment length polymorphism. Systematic and Applied Microbiology, 32(5): 342-350. https://doi.org/10.1016/j.syapm.2008.10.005

Lin W, Pan Y. 2009. Uncultivated magnetotactic cocci from Yuandadu Park in Beijing, China. Applied and environmental microbiology, 75(12): 4 046-4 052. https://doi.org/10.1128/AEM.00247-09

Lin W, Jogler C, Schuler D, et al. 2011. Metagenomic analysis reveals unexpected subgenomic diversity of magnetotactic bacteria within the phylum Nitrospirae. Applied and environmental microbiology, 77(1): 323-326. https://doi.org/10.1128/AEM.01476-10

Lin W, Li J, Pan Y. 2012a. Newly isolated but uncultivated magnetotactic bacterium of the phylum Nitrospirae 
from Beijing, China. Applied and environmental microbiology, 78(3): 668-675. https://doi.org/10.1128/aem.06764-11

Lin W, Wang Y, Li B, et al. 2012b. A biogeographic distribution of magnetotactic bacteria influenced by salinity. The ISME journal, 6(2): 475-479. https://doi.org/10.1038/ismej.2011.112

Lin W, Wang Y, Gorby Y, et al. 2013. Integrating niche-based process and spatial process in biogeography of magnetotactic bacteria. Scientific Reports, 3: 1 643. https://doi.org/10.1038/srep01643

Lin W, Deng A, Wang Z, et al. 2014. Genomic insights into the uncultured genus 'Candidatus Magnetobacterium' in the phylum Nitrospirae. The ISME journal, 8(12): 2 463-2 477. https://doi.org/10.1038/ismej.2014.94

Lin W, Pan Y. 2015. A putative greigite-type magnetosome gene cluster from the candidate phylum Latescibacteria. Environmental Microbiology Reports, 7(2): 237-242. https://doi.org/10.1111/1758-2229.12234

Lin W, Pan Y, Bazylinski D A. 2017. Diversity and ecology of and biomineralization by magnetotactic bacteria. Environmental microbiology reports, 9(4): 345-356. https://doi.org/10.1111/1758-2229.12550

Lin W, Zhang W, Zhao X, et al. 2018. Genomic expansion of magnetotactic bacteria reveals an early common origin of magnetotaxis with lineage-specific evolution. The ISME journal, 12(6): 1 508-1 519. https://doi.org/10.1038/s41396-018-0098-9

Lin W, Zhang W, Paterson G A, et al. 2020. Expanding magnetic organelle biogenesis in the domain Bacteria. Microbiome, 8(1): 152. https://doi.org/10.1186/s40168-020-00931-9

Liu J, Zhang W, Li X, et al. 2017. Bacterial community structure and novel species of magnetotactic bacteria in sediments from a seamount in the Mariana volcanic arc. Scientific Reports, 7(1): 17964. https://doi.org/10.1038/s41598-017-17445-4

Liu P, Liu Y, Zhao X, et al. 2021. Diverse phylogeny and morphology of magnetite biomineralized by $\begin{array}{lllllll}\text { magnetotactic cocci. } & \text { Environmental microbiology, } & \mathbf{2 3}(2): & 1 & 115-1 & 129 .\end{array}$ https://doi.org/10.1111/1462-2920.15254

Ma J, Song J, Li X, et al. 2019. Environmental characteristics in three seamount areas of the Tropical Western Pacific Ocean: Focusing on nutrients. Marine Pollution Bulletin, 143: 163-174. https://doi.org/10.1016/j.marpolbul.2019.04.045

Magoč T, Salzberg S L. 2011. FLASH: fast length adjustment of short reads to improve genome assemblies. Bioinformatics, 27(21): 2 957-2 963. https://doi.org/10.1093/bioinformatics/btr507

Martins J L, Silveira T S, Silva K T, et al. 2009. Salinity dependence of the distribution of multicellular magnetotactic prokaryotes in a hypersaline lagoon. International Microbiology, 12(3): 193-201. https://doi.org/10.2436/20.1501.01.98

Martins J L, Silveira T S, Abreu F, et al. 2012. Spatiotemporal distribution of the magnetotactic multicellular prokaryote Candidatus Magnetoglobus multicellularis in a Brazilian hypersaline lagoon and in microcosms. International Microbiology, 15(3): 141-149. https://doi.org/10.2436/20.1501.01.167

Meldrum F C, Mann S, Heywood B R, et al. 1993. Electron microscopy study of magnetosomes in a cultured coccoid magnetotactic bacterium. Proceedings of the Royal Society B, 251(1 332): 231-236. https://doi.org/10.1098/rspb.1993.0034

Mendonça A, Arístegui J, Vilas J C, et al. 2012. Is there a seamount effect on microbial community structure and biomass? The case study of Seine and Sedlo seamounts (Northeast Atlantic). PLoS One, 7(1): e29526. https://doi.org/10.1371/journal.pone.0029526

Moisescu C, Bonneville S, Staniland S, et al. 2011. Iron uptake kinetics and magnetosome formation by Magnetospirillum gryphiswaldense as a function of $\mathrm{pH}$, temperature and dissolved iron availability. Geomicrobiology Journal, 28(7): 590-600. https://doi.org/10.1080/01490451.2011.594146

Moisescu C, Ardelean, II, Benning L G. 2014. The effect and role of environmental conditions on magnetosome 
synthesis. Frontiers in Microbiology, 5: 49. https://doi.org/10.3389/fmicb.2014.00049

Moskowitz B M, Bazylinski D A, Egli R, et al. 2008. Magnetic properties of marine magnetotactic bacteria in a seasonally stratified coastal pond (Salt Pond, MA, USA). Geophysical Journal International, 174(1): 75-92. https://doi.org/10.1111/j.1365-246X.2008.03789.x

Pan H, Zhu K, Song T, et al. 2008. Characterization of a homogeneous taxonomic group of marine magnetotactic cocci within a low tide zone in the China Sea. Environmental microbiology, 10(5): 1 158-1 164. https://doi.org/10.1111/j.1462-2920.2007.01532.x

Petermann H, Bleil U. 1993. Detection of live magnetotactic bacteria in South Atlantic deep-sea sediments. Earth and Planetary Science Letters, 117(1-2): 223-228. https://doi.org/10.1016/0012-821X(93)90128-V

Popa R, Fang W, Nealson K H, et al. 2009. Effect of oxidative stress on the growth of magnetic particles in Magnetospirillum magneticum. International Microbiology, $\quad$ 12(1): $\quad 49-57$. https://doi.org/10.2436/20.1501.01.81

Pósfai M, Moskowitz B M, Arató B, et al. 2006. Properties of intracellular magnetite crystals produced by Desulfovibrio magneticus strain RS-1. Earth and Planetary Science Letters, 249(3-4): 444-455. https://doi.org/10.1016/j.eps1.2006.06.036

Pósfai M, Lefèvre C T, Trubitsyn D, et al. 2013. Phylogenetic significance of composition and crystal morphology of magnetosome minerals. Frontiers in Microbiology, 4: 344. https://doi.org/10.3389/fmicb.2013.00344

Postec A, Tapia N, Bernadac A, et al. 2011. Magnetotactic bacteria in microcosms originating from the French Mediterranean Coast subjected to oil industry activities. Microbial Ecology, 63(1): 1-11. https://doi.org/10.1007/s00248-011-9910-Z

Ruan J, Kato T, Santini C L, et al. 2012. Architecture of a flagellar apparatus in the fast-swimming magnetotactic bacterium MO-1. Proc. Natl. Acad. Sci. U. S. A., 109(50): 20643-20648. https://doi.org/10.1073/pnas.1215274109

Saitou N, Nei M. 1987. The neighbor-joining method: A new method for reconstructing phylogenetic trees. Molecular Biology and Evolution, 4(4): 406-425. https://doi.org/10.1093/oxfordjournals.molbev.a040454

Schüler D. 2002. The biomineralization of magnetosomes in Magnetospirillum gryphiswaldense. International microbiology, 5(4): 209-214. https://doi.org/10.1007/s10123-002-0086-8

Schübbe S, Williams T J, Xie G, et al. 2009. Complete genome sequence of the chemolithoautotrophic marine magnetotactic coccus strain MC-1. Applied and environmental microbiology, 75(14): 4 835-4 852. https://doi.org/10.1128/AEM.02874-08

Silva K T, Schüler M, Mickoleit F, et al. 2020. Genome-wide identification of essential and auxiliary gene sets for magnetosome biosynthesis in Magnetospirillum gryphiswaldense. mSystems, 5(6). https://doi.org/10.1128/mSystems.00565-20

Spring S, Lins U, Amann R, et al. 1998. Phylogenetic affiliation and ultrastructure of uncultured magnetic bacteria with unusually large magnetosomes. Archives of microbiology, 169(2): 136-147. https://doi.org/10.1007/s002030050553

Usui Y, Yamazaki T, Saitoh M. 2017. Changing abundance of magnetofossil morphologies in pelagic red clay around Minamitorishima, western North Pacific. Geochemistry Geophysics Geosystems, 18(12): 4 558-4 572. https://doi.org/10.1002/2017gc007127

Uzun M, Alekseeva L, Krutkina M, et al. 2020. Unravelling the diversity of magnetotactic bacteria through analysis of open genomic databases. Scientific Data, 7(1): 252. https://doi.org/10.1038/s41597-020-00593-0

Vali H, Förster O, Amarantidis G, et al. 1987. Magnetotactic bacteria and their magnetofossils in sediments. Earth and Planetary Science Letters, 86(2-4): 389-400. https://doi.org/10.1016/0012-821x(87)90235-4

Wang X K, Ma Q F, Jiang W, et al. 2008. Effects of hypomagnetic field on magnetosome formation of 
Magnetospirillum magneticum AMB-1. Geomicrobiology Journal, 25(6): 296-303. https://doi.org/10.1080/01490450802258295

Wolfe R S, Thauer R K, Pfennig N. 1987. A 'capillary racetrack' method for isolation of magnetotactic bacteria. FEMS Microbiology Ecology, 45(1): 31-35. https://doi.org/10.1016/0378-1097(87)90039-5

Xu C, Zhang W, Pan H, et al. 2018. Distribution and diversity of magnetotactic bacteria in sediments of the Yellow Sea continental shelf. Journal of Soils and Sediments, 18(7): 2 634-2 646. https://doi.org/10.1007/s11368-018-1912-8

Yamazaki T, Kawahata H. 1998. Organic carbon flux controls the morphology of magnetofossils in marine

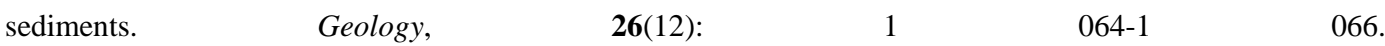
https://doi.org/10.1130/0091-7613(1998)026<1064:Ocfctm>2.3.Co;2

Yamazaki T, Shimono T. 2013. Abundant bacterial magnetite occurrence in oxic red clay. Geology, 41(11): 1 191-1 194. https://doi.org/10.1130/g34782.1

Yamazaki T, Suzuki Y, Kouduka M, et al. 2019. Dependence of bacterial magnetosome morphology on chemical conditions in deep-sea sediments. Earth and Planetary Science Letters, 513: 135-143. https://doi.org/10.1016/j.eps1.2019.02.015

Zhang H, Menguy N, Wang F, et al. 2017. Magnetotactic coccus strain SHHC-1 affiliated to Alphaproteobacteria forms octahedral magnetite magnetosomes. Frontiers in Microbiology, 8: 969. https://doi.org/10.3389/fmicb.2017.00969

Zhang W J, Santini C L, Bernadac A, et al. 2012. Complex spatial organization and flagellin composition of flagellar propeller from marine magnetotactic ovoid strain MO-1. Journal of Molecular biology, 416(4): 558-570. https://doi.org/10.1016/j.jmb.2011.12.065

Zhang W Y, Zhou K, Pan H M, et al. 2013. Novel rod-shaped magnetotactic bacteria belonging to the class Alphaproteobacteria. Applied and environmental microbiology, 79(9): $3 \quad 137-3 \quad 140$. https://doi.org/10.1128/AEM.03869-12

Zhang W Y, Pan H M, Dong Y, et al. 2019. Diversity of magnetotactic bacteria in intertidal sediments of Lake Yuehu, Rongcheng. Marine Sciences (in Chinese with English abstract), 43(03): 1-10. https://doi.org/10.11759/hykx20180925001

Zhou K, Zhang W-Y, Yu-Zhang K, et al. 2012. A novel genus of multicellular magnetotactic prokaryotes from the Yellow Sea. Environmental microbiology, 14(2): 405-413. https://doi.org/10.1111/j.1462-2920.2011.02590.x 